\title{
Kidney Measures to Improve Risk Discrimination of Cardiovascular Events
}

\author{
Hideki Ishii, MD, PhD; Toyoaki Murohara, MD, $\mathrm{PhD}$
}

M ore than 10 years have passed since cardiorenal interaction and cardiorenal syndrome were featured. ${ }^{1}$ Even if it is mild, renal dysfunction is related to a high incidence of cardiovascular disease (CVD). ${ }^{2,3}$ Indeed, an association between renal function and the unique characteristics of coronary plaque composition is considerable in the clinical setting. ${ }^{4,5}$ Some mechanisms are possible to explain such phenomena. Basically, other risk factors such as lifestyle disease are frequently seen in patients with chronic kidney disease (CKD). Recently, uremic toxin and inflammation were featured as targets to be treated in CKD patients. The malnutrition, inflammation and atherosclerosis (MIA) syndrome and protein energy wasting (PEW) have both been advocated to explain poor clinical outcomes in such populations. ${ }^{6,7}$

In this issue of the Journal, Matsushita et a ${ }^{8}$ clearly show that their "CKD patch" significantly improved the

\section{Article p 1876}

risk discrimination of CVD deaths in 3 very famous US cohorts, compared with only the traditional predictors. One of the important findings of the study is that the degree of improvement by adding kidney measurements was similar to fully refitting models. Traditionally, aging, presence of diabetes, hypertension, and dyslipidemia, and so on have been used to stratify high-risk populations. However, unfortunately, kidney measurements such as estimated glomerular filtration rate (eGFR) and presence of proteinuria have not been necessarily added as risk markers in guidelines for CVD. ${ }^{9}$

Once again, adding kidney measurements could demonstrate improvement in risk prediction, similar to fully adding many variables (Figure). In other words, eGFR and presence

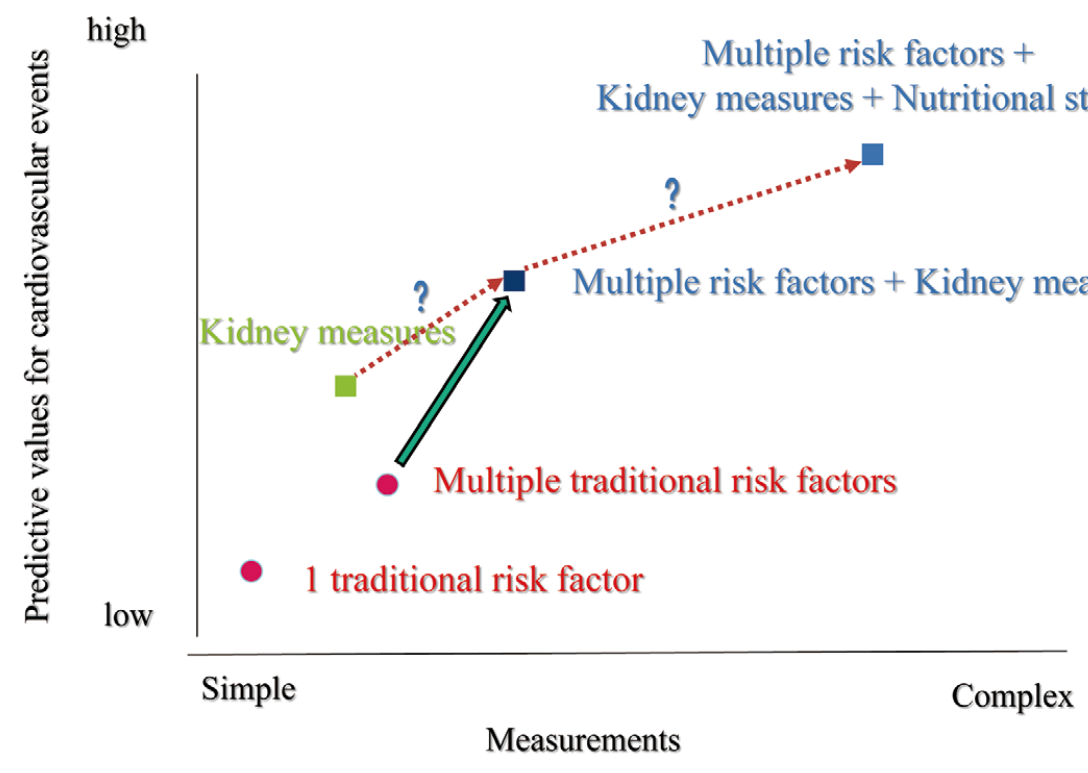

Figure. Relationship between measurement simplicity and predictive values for cardiovascular events.

The opinions expressed in this article are not necessarily those of the editors or of the Japanese Circulation Society.

Received July 1, 2019; accepted July 20, 2019; J-STAGE Advance Publication released online July 31, 2019

Department of Cardiology, Nagoya University Graduate School of Medicine, Nagoya, Japan

The Guest Editor for this article was Dr. Yoshihiko Saito.

Mailing address: Hideki Ishii, MD, PhD, Department of Cardiology, Nagoya University Graduate School of Medicine, 65

Tsurumai-cho, Showa-ku, Nagoya 466-8560, Japan. E-mail: hkishii@med.nagoya-u.ac.jp

ISSN-1346-9843 All rights are reserved to the Japanese Circulation Society. For permissions, please e-mail: cj@j-circ.or.jp 
of proteinuria might integrate such parameters. One problem in daily practice is that urinary testing, even dipstick, is frequently missing for patients with CVD, although eGFR is well checked in most cases. On this issue, there may be a discrepancy in the viewpoints of cardiologists and nephrologists. One of the main findings of the present study is that measurement of albuminuria was so important to detect patients at a high risk. Many studies have shown that the presence of micro- and macro-albuminuria is an independent risk factor for advanced atherosclerosis and cardiovascular events, apart from eGFR levels. ${ }^{10,11}$ Interestingly, 1 study using sequential computed tomography suggested a close association between advanced coronary atherosclerosis and decreased renal morphological changes. ${ }^{\mathbf{1 2}}$ Renal parenchymal volume may evaluate renal endocrine and tubular function in addition to filtration ability. Therefore, cardiologists as well as nephrologists should consider the meaning of kidney measurements.

It has been controversial to prescribe multiple antithrombotic agents in patients with CKD. Unfortunately, clinicians use some famous risk scores for ischemic and bleeding events in patients with atrial fibrillation and those after percutaneous coronary intervention, which do not include kidney measurements. In contrast, recent risk calculations, such as the CREDO-KYOTO risk score, include a factor of CKD. ${ }^{13}$ However, patients with CKD have very high scores for both ischemic and bleeding events. In other words, the trade-off for ischemic and bleeding events is very difficult in such subjects. A recent study suggested a relationship among nutritional status, inflammation and long-term bleeding events in patients treated with multiple antithrombotic agents. ${ }^{14}$ As shown in the concept of MIA syndrome, nutritional status is a key point in the CKD population. ${ }^{5}$ Therefore, nutritional status in addition to kidney measurements might improve risk prediction in prognosis and advanced atherosclerosis or arteriosclerosis compared with previously suggested models ${ }^{\mathbf{1 5}}$ (Figure). Particularly in Japan, unique approaches are warranted because a super-old society is advancing, ahead of any other country in the world.

Simple methods that can predict clinical outcomes and contribute to timely therapeutic interventions are attractive. Kidney measurements may be just the ones: 'Est! Est!! Est!!! di Montefiascone'.

\section{Disclosures}

H. Ishii received lecture fees from Astellas Pharma Inc., Astrazeneca Inc., Bayer Pharmaceutical Co., Ltd., Bristol-Myers Squibb Inc., Chugai Pharmaceutical Co., Ltd., Daiichi-Sankyo Pharma Inc., and MSD K. K. T. Murohara received lecture fees from Bayer Pharmaceutical Co., Ltd., Daiichi-Sankyo Co., Ltd., Dainippon Sumitomo Pharma Co., Ltd., Kowa Co., Ltd., MSD K. K., Mitsubishi Tanabe Pharma Co., Nippon Boehringer Ingelheim Co., Ltd., Novartis Pharma K. K., Pfizer Japan Inc., Sanofi-aventis K. K., and Takeda Pharmaceutical Co., Ltd.; unrestricted research grant for Department of Cardiology, Nagoya University Graduate School of Medicine from Astellas Pharma Inc., Daiichi-Sankyo Co., Ltd., Dainippon Sumitomo Pharma Co., Ltd., Kowa Co., Ltd., MSD K.
K., Mitsubishi Tanabe Pharma Co., Nippon Boehringer Ingelheim Co., Ltd., Novartis Pharma K. K., Otsuka Pharma Ltd., Pfizer Japan Inc., Sanofi-aventis K. K., Takeda Pharmaceutical Co., Ltd., and Teijin Pharma Ltd.

\section{References}

1. Ronco C, Haapio M, House AA, Anavekar N, Bellomo R. Cardiorenal syndrome. J Am Coll Cardiol 2008; 52: 1527-1539.

2. Mann JF, Gerstein HC, Pogue J, Bosch J, Yusuf S. Renal insufficiency as a predictor of cardiovascular outcomes and the impact of ramipril: The HOPE randomized trial. Ann Intern Med 2001; 134: $629-636$

3. Mok Y, Ballew SH, Matsushita K. Prognostic value of chronic kidney disease measures in patients with cardiac disease. Circ $J$ 2017; 81: 1075-1084

4. Miyagi M, Ishii H, Murakami R, Isobe S, Hayashi M, Amano T, et al. Impact of renal function on coronary plaque composition. Nephrol Dialysis Transplant 2010; 25: 175-181.

5. Nakano T, Ninomiya T, Sumiyoshi S, Fujii H, Doi Y, Hirakata $\mathrm{H}$, et al. Association of kidney function with coronary atherosclerosis and calcification in autopsy samples from Japanese elders: The Hisayama study. Am J Kidney Dis 2010; 55: 21-30.

6. Stenvinkel P, Heimbürger O, Paultre F, Diczfalusy U, Wang T, Berglund L, et al. Strong association between malnutrition, inflammation, and atherosclerosis in chronic renal failure. Kidney Int 1999; 55: 1899-1911.

7. Fouque D, Kalantar-Zadeh K, Kopple J, Cano N, Chauveau P, Cuppari L, et al. A proposed nomenclature and diagnostic criteria for protein-energy wasting in acute and chronic kidney disease. Kidney Int 2008; 73: 391-398.

8. Matsushita K, Sang Y, Chen J, Ballew SH, Shlipak M, Coresh J, et al. Novel "predictor patch" method for adding predictors using estimates from outside datasets: A proof-of-concept study adding kidney measures to cardiovascular mortality prediction. Circ J 2019; 83: 1876-1882.

9. Goff DC Jr, Lloyd-Jones DM, Bennett G, Coady S, D'Agostino RB, Gibbons R, et al. 2013 ACC/AHA guideline on the assessment of cardiovascular risk: A report of the American College of Cardiology/American Heart Association Task Force on Practice Guidelines. Circulation 2014; 129: S49-S73.

10. Shimbo Y, Suzuki S, Ishii H, Shibata Y, Tatami Y, Harata S, et al. Association of estimated glomerular filtration rate and proteinuria with lipid-rich plaque in coronary artery disease. Circ J 2015; 79: 2263-2270.

11. Mok Y, Ballew SH, Sang Y, Grams ME, Coresh J, Evans M, et al. Albuminuria as a predictor of cardiovascular outcomes in patients with acute myocardial infarction. J Am Heart Assoc 2019; 8: e010546.

12. Ichii T, Morimoto R, Okumura T, Ishii H, Tatami Y, Yamamoto $\mathrm{D}$, et al. Impact of renal functional/morphological dynamics on the calcification of coronary and abdominal arteries in patients with chronic kidney disease. J Atheroscler Thromb 2017; 24: $1092-1104$.

13. Natsuaki M, Morimoto T, Yamaji K, Watanabe H, Yoshikawa $\mathrm{Y}$, Shiomi H, et al. Prediction of thrombotic and bleeding events after percutaneous coronary intervention: CREDO-Kyoto Thrombotic and Bleeding Risk Scores. J Am Heart Assoc 2018; 7: $\mathrm{e} 008708$.

14. Yoshida R, Ishii H, Morishima I, Tanaka A, Morita Y, Takagi K, et al. Impact of nutritional and inflammation status on long-term bleeding in patients undergoing percutaneous coronary intervention with an oral anticoagulant. J Atheroscler Thromb, doi:10.5551/ jat.47654.

15. Harada K, Suzuki S, Ishii H, Hirayama K, Aoki T, Shibata Y, et al. Nutritional status predicts severity of vascular calcification in non-dialyzed chronic kidney disease patients. Circ J 2017; 81: $316-321$. 